\title{
ESPORTIVIZAÇÃO DE UM JOGO: ALGUMAS CONSIDERAÇÕES SOBRE O FUTSAC
}

DOI: $105902 / 0102830822293$

Data de submissão: 18-05-2016

Data de Aceite: 01-07-2016

Simone Rechia

Universidade Federal do Paraná

simone@ufpr.br

Gabriela Cardoso Machado

Universidade Federal do Paraná

gabrielacardosomachado@gmail.com

\author{
Aline Tschoke \\ Instituto Federal do Paraná \\ aline_tschoke@yahoo.com.br \\ Daniela Tschoke Santana \\ Universidade Federal do Paraná \\ dani.tschoke@gmail.com
}

Resumo: Esta pesquisa buscou investigar qualitativamente como uma prática corporal criada na cidade de Curitiba-PR, especificamente o Futsac, passou pelo processo de esportivização. Para isso, foram realizados: levantamento de dados do acervo digital da Confederação Brasileira de Futsac e entrevista semiestruturada com o criador do esporte. Identificamos nesse contexto algumas elementos diretamente relacionados a transformação desse jogo em esporte, sendo estes: estratégias para regulamentar e divulgar a prática, com destaque para estabelecimento de parcerias, papel dos idealizadores, organizadores e atletas.

Palavras-chave: Futsac. Jogo. Esportivização. 


\section{Introdução}

O Futsac, acrônimo de "Futebol de Saco", é o sexto esporte oficialmente criado no Brasil e o primeiro criado na cidade de Curitiba- PR. Por isso, optamos por investigar como essa prática corporal passou pelo processo de esportivização.

Em uma primeira análise, percebemos que para atingir nosso objetivo faz-se necessário primeiro tratarmos as diferenças entre os conceitos de jogo e esporte. O jogo é definido por Huizinga (2000) como uma atividade voluntária executada em espaço e tempo determinados, obrigatoriamente regrado com finalidade em si mesmo, levando consigo momentos de tensão e alegria diferentes do mundo real. Em seu livro Homo Ludens, o mesmo autor trata o jogo como categoria essencial da vida, tão necessária quanto o raciocínio (Homo sapiens) e a produção de objetos (Homo faber), nos fazendo entender a dimensão lúdica como fundamental no surgimento e no desenvolvimento da civilização.

Segundo Bruhns (1999), o jogo tem por essência ser uma atividade lúdica, livre, que pode por vezes ser competitiva. Tais experiências para a autora são por excelência integradoras, tendo como características principais a espontaneidade e a construção coletiva das regras. Ainda de acordo com Bruhns (1996, p.35) o jogo tem no lúdico seu componente mais expressivo, "[...] há espaço para a liberdade e a criatividade encontra-se presente".

Dessa forma, alguém que joga descobre e adapta a realidade dos jogos às suas necessidades cotidianas. Essas vivências poderão motivar a querer descobrir algo novo ajudando no desenvolvimento de aspectos fundamentais para o convívio social como construção e respeito às normas, liderança, cooperação, entre outras.

Já o esporte caracteriza-se por sua institucionalização, sendo estritamente competitivo regido por regras e procedimentos geralmente universais, tendo identidade própria, sendo embasado tecnicamente e tendo cada modalidade definida por seus gestos técnicos singulares, que incide sob condições formais e organizadas. Geralmente no esporte o resultado e o desempenho são os interesses buscados.

A partir do momento que tal prática corporal se transforma em uma atividade seletiva, que requer habilidades muito bem desenvolvidas para buscar a vitória, deixa de lado as características principais do jogo e se torna um esporte que busca o alto rendimento. 
O esporte pode ser entendido de formas diferenciadas tais como: esporte recreativo, esporte educativo e esporte de rendimento ou espetáculo. O primeiro ligado ao esporte como direito de todos, onde cada pessoa pode ter acesso à aprendizagem de práticas esportivas/recreativas. Assim o esporte educativo tem como objetivo apoiar a formação de atletas e incentivar à integração cultural e social de diferentes sociedades. Já o esporte de rendimento ou espetáculo vem juntamente com o interesse destacado pela mídia, objetivando renúncia fiscal como também benefício econômico e político (THOMAZ, 2010).

Como afirma Brohm (1978, p. 18 apud STIGGER, 2002, p. 25)

[...] esporte é uma parte integrada na totalidade concreta: a sociedade capitalista e seu dinamismo, sendo que a sua função social e política [...] Ihe é ditada pelo lugar que ocupa dentro da totalidade das relações sociais.

Contudo, em contraposição a esse tema Rosa e Costa (2010) ressaltam que há necessidade de olharmos também para o esporte sob outro prisma, como momento de ressignificação de valores dentro de "novas" práticas esportivas. Estas que podem se preocupar não apenas com o desenvolvimento simbólico e ético do indivíduo, mas também com a promoção da saúde, a interação social, ou seja, com uma vida de qualidade.

Tendo em vista estes conceitos, a transformação de um jogo em esporte pode demudar uma experiência puramente brincante do sujeito, que intenciona simplesmente divertir-se, para uma experiência competitiva, sustentada em princípios do esporte de rendimento.

Nesse sentido, o processo de transformação de um jogo em esporte é denominado esportivização, termo que pode ser definido segundo González como:

(...) ato ou efeito de transformar uma prática corporal em esporte, assumindo os códigos próprios desse fenômeno. Por Adorno é um tipo de socialização que tem origem no esporte-espetáculo e na relação do público com ele (GONZÁLEZ, 2010, p. 170).

Ou seja, atividades inicialmente não esportivas incorporam as características, códigos e princípios deste fenômeno. Sendo assim, buscamos analisar o caso do Futsac e como este, de jogo passou a se tornar um esporte. 
Em uma abordagem qualitativa, foram seguidos os seguintes passos metodológicos: (1) levantamento de dados do acervo digital da Confederação Brasileira de Futsac; (2) entrevista semiestruturada com o criador do Futsac - entrevistado A. (3) Descrição do processo de esportivização.

\section{FUTSAC: Trajetória do Jogo ao Esporte}

Em 1998, o idealizador do esporte, durante um intercâmbio na Austrália, entrou em contato com um jogo chamado Footbag, no qual a pessoa faz malabarismos de estilo livre com os pés e uma pequena bola cheia de grãos plásticos. Em 2002, tendo este jogo como inspiração, o Futsac começou a ser desenvolvido no Brasil.

As inspirações também vieram de diferentes modalidades esportivas, desde as conhecidas nacionalmente como o Futevôlei, o Futebol e o Tênis, assim como outras menos populares a exemplo do Sepak-Takraw, praticado no sudeste asiático. Essa mistura deu origem ao Futsac como uma nova prática de metodologias e regras específicas, que associa os instintos naturais do corpo como coordenação, domínio de espaço, reflexo e equilíbrio, inerentes a todos os seres humanos.

O Futsac pode ser jogado individualmente ou em dupla, na forma de esporte é jogado em uma quadra de 10 metros de comprimento por 5 metros de largura, separada por uma rede de 1 metro e 50 centímetros de altura. O objetivo principal é fazer a bolinha, específica do Futsac, ultrapassar a rede e cair no campo do adversário que, por sua vez, tem o objetivo de não deixá-la cair, devolvendo-a em direção a quadra do oponente. Quando a bolinha tocar o chão ou em uma das linhas é contabilizado um ponto para a equipe que a lançou. Para golpear a bolinha, podem ser utilizados os pés, pernas, tronco e cabeça, sendo vedado apenas o uso das mãos e braços no modelo de jogo oficial. O número de toques na bolinha varia de acordo com a quantidade de jogadores e as situações de jogo. Quem conquistar 2 sets (compostos cada um por 21 pontos corridos) vence a partida. 
A bolinha do Futebol de Saco é uma adaptação em relação à do Footbag, visto que seu criador não encontrou modelo similar no Brasil. Desta forma, buscou desenvolver uma bolinha composta de plástico granulado, reciclado de garrafa PET, envolvido por um tecido suplex que serve como uma bolsa para segurar os grãos, sendo esta revestida por uma camada de crochê. O crochêé elaborado por crocheteiras vinculadas àAssociação Curitibana de Crochê, com a qual foi firmada uma parceria, estabelecida desde o desenvolvimento dos primeiros protótipos das bolinhas em 2001, como forma de auxiliar na renda familiar das associadas. Destaca-se que esse processo contribui como um valor agregado de responsabilidade social e ambiental do Futsac.

Hoje o Futsac constitui-se como uma modalidade consolidada e oficializada, ou seja, é respaldada por uma confederação, a CBFSAC - Confederação Brasileira de Futsac e reconhecida pelo Ministério do Esporte. Oficialmente, já foram realizados mais de 40 campeonatos, desde competições estaduais a nacionais. Os maiores polos de atletas de Futsac estão nos estados do Paraná, Santa Catarina e Rio Grande do Sul.

No entanto, o Futsac nem sempre se encontrou na condição de esporte, trata-se de uma prática que passou por um processo de esportivização. E é sobre este processo que o presente artigo pretende discorrer.

O Futsac, segundo entrevista concedida pelo seu idealizador (Entrevistado A), teve sua origem a partir de um jogo realizado em círculo, tendo como essência ser "soma-zero", que não existe pontuação e constitui uma situação "ganha-ganha", ou seja, não há vencedores. É uma forma de jogo cooperativa, pois as pessoas envolvidas na prática não competem entre si e sim cooperam uns com os outros para atingir o objetivo em comum, que é manter a bolinha no ar, golpeando-a preferencialmente com os pés, pernas, cabeça e tronco, mas não impossibilitando a utilização de mãos e braços no jogo em círculo. As regras do jogo em círculo são estabelecidas por decisão dos participantes e podem ser alteradas a qualquer momento, sendo flexíveis (como o recurso de utilizar as mãos, que é usado inclusive para a iniciação esportiva do Futsac). Não há limite de jogadores e não há exigência de resultados.

O jogo realizado em círculo, fora da quadra, emprega o recurso de utilizar as mãos quando este é usado inclusive para a iniciação no Futsac enquanto esporte, conforme afirma o entrevistado A. 
Toda iniciação ao Futsac é estimulada a ser feita com o jogo em círculo, pois a criança ou qualquer pessoa que conhecer o Futsac diretamente na quadra se desmotiva e perde o interesse, por ser um esporte difícil, que requer habilidades bem desenvolvidas para passar a bolinha por cima da rede sem poder usar as mãos.

Um aspecto relevante no início da popularização do Futsac foi a ênfase dada a essa parte recreativa do jogo, de forma espontânea e desafiadora, buscando inventar formas criativas de execução, com diferentes partes do corpo. Esta flexibilização torna a atividade mais fácil de ser realizada, exigindo menos habilidades específicas, sendo mais acessível a todos. Reforçando o berço do Futsac enquanto jogo, que está relacionado ao primeiro contato que seu criador teve no exterior com amigos que jogavam o Footbag.

Os praticantes tinham um jeito alegre de se encontrar para jogar, tiravam a bolinha do bolso e se punham a trocar lances ministrando a pequena bolinha com os pés (Entrevistado A).

Constata-se que as primeiras manifestações do Futsac se apresentam enquanto jogo, uma vez que os elementos criatividade, espontaneidade e flexibilidade das regras e de participantes são predominantes. Entretanto com o passar do tempo essa forma de jogar em círculo foi se especializando e vinculando-se a alguns aspectos competitivos, ou seja, se passou a valorizar mais elementos que remetem ao caráter esportivo da prática em relação à ação lúdica pura que, mesmo permeada pelas regras e normas criadas, para alguns, continua sendo a parte mais atraente da prática, eternizada como forma de aquecimento antes das competições oficiais na quadra.

Quando a prática do Futsac passa a acontecer como descrito no início deste trabalho, em uma quadra delimitada, com regras "universais" instauradas, número de participantes limitado e jogando uns contra os outros, como adversários (e não mais em cooperação total em prol de um objetivo comum), com a presença de juízes normatizando as ações e quando órgãos responsáveis que administram todos estes elementos são criados, é que se percebe o início da trajetória de transformação do jogo em esporte, ou seja, do processo de esportivização do Futsac. 
Visto que é no processo de esportivização do Futsac institucionalizado na quadra, que ocorre uma maior disseminação da modalidade, a partir do apoio e patrocínio de entidades esportivas e políticas, por meio de redes sociais, demonstrações do esporte em diversas cidades do país, organização de campeonatos, implantação de quadras em escola públicas e particulares, e em locais públicos das cidades como praças e parques. Assim como cursos de formação e capacitação de árbitros que também compuseram toda essa trajetória.

O Futsac foi assim ganhando cada vez mais adeptos, até que o primeiro campeonato oficial foi realizado, em 2007, na cidade de Curitiba-PR. As cenas do cotidiano do Futsac revelam histórias inusitadas, como as que aconteceram no primeiro campeonato catarinense, realizado em 2008 na cidade de Itapema com atletas dos Paraná e Santa Catarina, em que mostrou a potencialidade do esporte, apropriado principalmente pelos jovens. Os árbitros e até mesmo o idealizador da prática ficaram espantados com o nível de jogabilidade que os meninos já estavam inferindo ao Futsac na quadra. Neste mesmo ano o Futsac foi reconhecido pela prefeitura de Curitiba, como um esporte oficialmente criado na cidade.

Ainda no final de 2008, também em Itapema, foi realizado o primeiro campeonato brasileiro de Futsac, a partir daí surgem grandes craques do esporte em Santa Catarina. O entrevistado A conta que pelo fato da cidade ser pequena ele teve mais facilidade e liberdade para poder implantar três quadras de Futsac em uma praça principal da cidade, proporcionando aos atletas se reunirem diariamente para treinar. Uma história interessante é que os meninos marcavam até de treinar pela madrugada:

Eles chamavam os encontros de "madrugadão", pediram para o prefeito colocar iluminação, porque eles trabalhavam o dia todo então começavam às 22 horas e jogavam até às 4 horas da manhã no "madrugadão", levavam garrafão de água e jogavam empolgados, foi assim que o nível de jogo dos meninos de Santa Catarina subiu muito. Porque aqui em Curitiba a gente não tinha quadra pública ainda, só tínhamos uma aqui da federação, e lá por ser praça aberta todos jogavam, então eles tinham mais de 30 pessoas boas jogando. É como em outros esportes, você jogando com várias pessoas o nível aumenta, daí começou a surgir um campeão, o nosso Kelly Slater do Futsac, o Willian Alves, que dos 5 brasileiros que ele competiu ele ganhou os 5 , ele tem um jeito só dele de jogar, parece que a bolinha para no ar, de tão tranquilo que ele joga. Em paralelo a esse período de 2008, começou também a ter atletas em Blumenau, logo em 2009 fundamos a federação catarinense (Entrevistado A). 
A partir dessa adesão da prática do Futsac no tempo de lazer, o esporte passa a ganhar cada vez mais espaço entre as práticas realizadas, principalmente pelos jovens, em seu tempo livre.

\section{Segundo a CBFSAC}

Em 2009 foi criada a Federação Paranaense de Futsac - FPFSAC e o esporte começou a ser mais difundido na cidade de Curitiba. Em 2010 foram construídas as primeiras quadras públicas de Futsac no Parque Barigui em Curitiba. Em 2011 foi realizada uma cerimônia oficial nestas quadras públicas para o reconhecimento do Futsac como um esporte oficialmente Paranaense. Em 2013 foram oficialmente criadas a Federação Catarinense de Futsac - FCFSAC, com sede em Itapema/ SC e a Federação Gaúcha de Futsac - FGFSAC, com sede em Lajeado/RS (CBFSAC).

O Futsac como esporte foi sendo introduzido e apresentado em vários colégios e universidades de Curitiba, além de outras instituições. Existem quadras fixas em 12 escolas da rede municipal de ensino em parceria com o projeto Comunidade Escola, proporcionando aos jovens estudantes conhecer, segundo o criador da ideia, uma "nova modalidade esportiva" (Entrevistado A).

No entanto, para se tornar um esporte oficial, uma prática corporal precisa passar por diversos trâmites até que seja institucionalmente reconhecida. O Ministério do Esporte exige a existência de no mínimo três federações para reconhecer uma modalidade.

Com a existência das Federações Paranaense, Catarinense e Gaúcha, para completar os procedimentos, no final de 2013 foi criada a Confederação Brasileira de Futsac - CBFSAC, com sede na cidade de Curitiba.

Já estruturado, atendendo às exigências básicas e em franco crescimento no país, o Futsac conquistou a chance de ser oficializado como a primeira modalidade esportiva criada no Paraná.

Segundo o Conselho Regional de Educação Física do Paraná, 
Neste período, de 2002 até hoje, foram criadas regras bem definidas, metodologia de ensino e aprendizagem, implantação em parques e escolas, formação de árbitros, campeonatos regionais e nacionais... enfim, o Futsac passou por todos os processos de criação, adaptação e estruturação de um novo esporte (CREF, abril de 2014).

Segundo a CBFSAC, "a cerimônia de oficialização do Futsac aconteceu na Praça Oswaldo Cruz, em Curitiba no dia 29 de março de 2014, aniversário da cidade" e contou com a presença de diversas autoridades, como prefeito da cidade, secretários, diretores e vereadores, além de atletas e responsáveis pelas federações. Enfim, o Futsac torna-se um esporte oficialmente reconhecido.

Mesmo oficializado como esporte, o período de tempo corrido que o Futsac passou desde seu surgimento até o momento atual é muito curto, dessa forma ainda não há registros de atletas que têm a prática do Futsac como sua fonte de sustento, ou seja, não foram encontrados atletas profissionais de Futsac. Sendo assim, e considerando principalmente questões como, por exemplo, as já supracitadas acerca dos "madrugadões", percebemos que a grande maioria dos jogadores realizam a prática depois do tempo do trabalho ou nos finais de semana, ou seja, escolheram a modalidade para fruição no seu tempo livre, no tempo de lazer.

No entanto, o formato como o Futsac vem sendo desenvolvido se aproxima com a proposta elaborada pelo autor canadense Robert Stebbins (apud Oliveira \& Doll, 2012; 2014). Este autor propõe a "Perspectiva do Lazer Sério", composta por três tipos: lazer sério, lazer casual e o lazer baseado em projeto. Para os fins deste trabalho o foco será principalmente sobre o conceito de lazer sério, apresentado como (Stebbins apud Oliveira \& Doll, 2012, p.327):

[...] a prática sistemática de uma atividade por amadores, praticantes de hobby ou voluntários, considerada substancial, interessante e realizadora que em casos típicos, lança-lhes numa carreira (de lazer) centrada na aquisição e expressão de uma combinação de habilidades especiais, conhecimento e experiência.

NocasodoFutsac, observamosquea prática pode seramadoraou hobby, em suas manifestações de esporte ou jogo, respectivamente. Em se tratando do estilo amador percebemos que vários atletas competem e "levam a sério" o Futsac como esporte, se especializando cada vez mais e desenvolvendo as habilidades necessárias, a ponto de serem lançados nesta carreira de lazer como fala o autor. 
Assim como o jogo do Futsac pode se tornar um hobby para seus praticantes, sem a necessidade de competir, o que não minimiza a seriedade e comprometimento com a prática quando, por exemplo, um grupo se encontra regularmente para jogar.

Nesta perspectiva do lazer sério, são elencadas seis "qualidades distintivas" (Stebbins, 2008, p.11-13 apud Oliveira \& Doll, 2014):

1. Perseverança: "como uma necessidade ocasional que surge e se apresenta aos praticantes do 'lazer sério' em casos em que enfrentam situações adversas decorrentes de suas práticas" (idem, p.7), motor para a próxima qualidade;

2. Carreira: "[...] ligada a continuidade na atividade, tanto em períodos de aumento de prestígio e benefícios, quanto na diminuição destes" (idem, p.8), que pode ser dividida em quatro estágios:

[...] o de iniciação, em que os praticantes adquirem as habilidades ou conhecimentos específicos da atividade de lazer; o desenvolvimento, em que os praticantes aprimoram essas habilidades ou conhecimentos; o estabelecimento, em que os praticantes do lazer alcançam relativa estabilidade em suas habilidades e conhecimentos; o estágio de manutenção, em que os praticantes buscam manter suas habilidades e conhecimentos nos mais altos níveis; e o declínio e afastamento (idem, p.8)

3. Esforço: “o praticante do 'lazer sério' necessita esforçar-se empenhando e desenvolvendo seu conhecimento, treino, experiência ou habilidades" (Oliveira \& Doll 2012, p. 328);

4. Benefícios duráveis: "reúne benefícios de ordem emocional e social, identificados em maior parte entre os amadores" (idem);

5. Mundo social específico: "se desenvolve em torno das outras qualidades. O ethos é entendido com o espírito dos participantes da comunidade do lazer sério, manifestada por suas atitudes compartilhadas, práticas, valores, objetivos e assim por diante" (ibidem);

6. Identificação: "identificarem-se fortemente uns com os outros" (Oliveira \& Doll, 2014, p.10).

Destas qualidades, podemos destacar que a soma de todas elas se aproximam do Futsac enquanto esporte, uma vez que, principalmente perseverança, carreira e esforço são indispensáveis à continuidade na forma esportivizada da atividade já que, como mencionamos anteriormente, são exigidas habilidades muito bem desenvolvidas para o que o Futsac tenha certa dinâmica quando jogado em quadra. 
Como também, algumas das qualidades elencadas podem ser associadas ao Futsac jogo, já que benefícios duráveis, mundo social específico e identificação fazem parte do pertencer a um grupo que possui uma prática em comum e que compartilham do reconhecimento e dos benefícios, mas também dos custos e das tensões que podem surgir em torno da prática.

Percebemos então que mesmo esportivizado o Futsac em suas ambas formas, se relaciona com a perspectiva do lazer sério e também com outros conceitos que a permeiam, tais como organização, comunidade, história, estilo de vida e cultura (Stebbins apud Oliveira \& Doll, 2012). O que notamos é que estas características também influenciaram na consolidação do Futsac enquanto uma prática corporal possível, contribuindo igualmente no seu processo de esportivização.

\section{Considerações Finais}

A partir da história do Futsac, podemos concluir que é mais uma dentre inúmeras práticas corporais que passaram por um processo de esportivização. Depois de uma longa trajetória atualmente se tem uma composição legislativa, executiva e estrutural em torno da prática, o que a configura como um esporte, de modo a potencializar sua consolidação.

Percebemos neste processo a importância das parcerias entre associações, organizações, atletas e atores políticos na divulgação da modalidade em um cenário inicialmente regional, ampliando o alcance até a esfera nacional. Assim os protagonistas da consolidação do Futsac tem papel fundamental neste processo, já que são estas figuras que movimentam e auxiliam na divulgação para aumentar a adesão ao Futsac.

É preciso deixar claro que, embora o esporte e seus aspectos competitivos, de rendimento, de lucro e de espetáculo sejam muitas vezes vistos em detrimento do jogo e sua ludicidade, o fato de uma modalidade se transformar em esporte não necessariamente suprime sua manifestação enquanto jogo.

O que muitas vezes ocorre, tanto no caso do Futsac como em outros tipos de modalidades esportivas é que, mesmo havendo as normativas exigidas para o esporte oficial, ainda enquanto jogo estas atividades podem ser praticadas com liberdade e 
finalidade lúdica, com as regras acordadas pelos participantes.

O Entrevistado A, em relação ao jogo, afirma que:

[...] toda iniciação ao Futsac é estimulada a ser feita com o jogo em círculo, pois a criança ou qualquer pessoa que conhecer o Futsac diretamente na quadra se desmotiva e perde o interesse, por ser um esporte difícil, que requer habilidades bem desenvolvidas para passar a bolinha por cima da rede sem poder usar as mãos.

Daí a importância da valorização de uma prática enquanto jogo, pois além de todos os benefícios que o jogar proporciona (socialização, interação, desenvolvimento de habilidades, criatividade, etc) ela pode facilitar e ajudar a promover esta mesma prática na condição de esporte. No caso do Futsac, essa relação é essencial.

\section{Referências}

BRUHNS, H. T. O corpo parceiro e o corpo adversário. Campinas: Papirus, 1999.

BRUHNS, H. O jogo nas diferentes perspectivas teóricas. Motrivivência, São Paulo, VIII (9), p. 27-43, dez. 1996.

CBFSAC. Confederação Brasileira de Futsac. Disponível em: <http://www.futsac.com>. Acesso em 04/03/2015.

CREF. Conselho Regional de Educação Física. Disponível em: <http://www.crefpr.org. $\mathrm{br} / \mathrm{p}=6241>$. Acesso em 04/03/2015.

GONZÁLEZ, F. J. Esportivização. In: GONZÁLEZ, F. J.; FENSTERSEIFER, P. E. (Org.) Dicionário Crítico da Educação Física. ljuí: Unijuí , 2010. p. 170-174.

HUIZINGA, J. Homo Ludens: o jogo como elemento da cultura. São Paulo: Perspectiva, 2000. 
ROSA, S. T. e COSTA, S. B. A Prática Esportiva Crítico Social. Revista Digital. Buenos Aires, Ano 14, n 142. Março de 2010

STTIGER, M. P. Esporte, lazer e estilos de vida: um estudo etnográfico. Campinas: Autores Associados, 2002.

OLIVEIRA, S. N.; DOLL, J. Serious Leisure. Movimento, Porto Alegre, v.18, n.01, p.325-338, jan/mar de 2012.

THOMAZ, F. O. Políticas esportivas. In: GONZÁLEZ, F. J.; FENSTERSEIFER, P. E. (Org.) Dicionário Crítico da Educação Física. ljuí: Unijuí , 2010. p. 327-335. 


\section{SPORTIVIZATION OF A GAME: SOME CONSIDERATIONS OF FUTSAC}

Abstract: This research investigates how this process of sportivization the Futsac happened. These is a genuinely Curitiba sport, is a practice that is growing in Brazil. Initially a game, today has been formalized as a sport. For this, a qualitative approach was carried out: data collection in the digital collection of the Brazilian Confederation of Futsac and a semi-structured interview with the creator of the sport. That partnering is critical to sportivization process: ways off organs that regulate and disclosure, like the federations and the confederation, not forgetting also the role of creators, organizers and athletes.

Keywords: Futsac. Game. Sportivization

\section{LA ESPORTIVIZACIÓN DE UM JUEGO: ALGUNAS CONSIDERACIONES ACERCA DEL FUTSAC}

Resumen: Esta investigación tuvo cómo fue investigar cualitativamente como una práctica corporal establecida, específicamente Futsac, pasó sportivization proceso. Para tanto, un enfoque cualitativo se llevó a cabo: la recopilación de datos de colecciones digitales de la Confederación Brasileña de Futsac y una entrevista semiestructurada con el creador de este deporte. Identificamos esse que la asociación es fundamental para el proceso de sportivization, y la estructuración de la actividad en los órganos que regulan y colaboran principalmente en la divulgación, como las federaciones y la confederación, sin olvidar también el papel de los creadores, organizadores y atletas.

Palabras clave: Futsac. Juego. Esportivización. 